\title{
The Sense of Coherence: Measurement Issues
}

\author{
Monica Eriksson and Paolo Contu
}

\section{Introduction}

Antonovsky (1987) developed a questionnaire to measure the sense of coherence. The original form, the Orientation to Life Questionnaire, consists of 29 items, 11 items measuring comprehensibility, 10 items measuring manageability, and 8 items measuring meaningfulness. The response alternatives are a semantic scale of 1 point to 7 points, where 1 and 7 indicate extreme feelings about questions (and statements) about how one's life is experienced (e.g., the question "when you talk to people, do you have the feeling that they do not understand you?" is scored from 1 = never have this feeling to 7 = always have this feeling). The questionnaire is a summed index with a total score ranging from 29 to 203 points for the original scale of 29 questions (SOC-29). A shorter version of 13 questions (SOC-13) of the original form was developed by Antonovsky (1987), where the score ranges between 13 and 91 points. Antonovsky intended that the sense of coherence scales be scored with a single total score and not component scores (Fig. 11.1) since he theorized that it was the sense of coherence in its totality that influenced movement along the ease/dis-ease continuum. This issue is taken up again later in this chapter.

This chapter is a revision and update of work published in Mittelmark, M.B., Sagy, S., Eriksson, M., Bauer, G., Pelikan, J.M., Lindström, B., \& Espnes, G.A. (eds). (2017). The Handbook of Salutogenesis. Springer, Cham. https://doi.org/10.1007/978-3-319-04600-6.

\section{Eriksson ( $\square)$}

Department of Health Sciences, Section of Health Promotion and

Care Sciences, Center on Salutogenesis, University West,

Trollhättan, Sweden

e-mail: monica.eriksson@hv.se

\section{P. Contu}

Department of Medical Sciences and Public Health, University of

Cagliari, Cittadella Universitaria, Monserrato-Cagliari, Italy

\section{SENSE OF COHERENCE (SOC)}

\section{Comprehensibility $\Longleftrightarrow$ Manageability $\Longleftrightarrow$ Meaningfulness}

Fig. 11.1 The original view of the sense of coherence and its three dimensions

Examples of items measuring the comprehensibility dimension are as follows (Antonovsky, 1987, p. 190ff.):

- When you talk to people, do you have a feeling that they don't understand you? (from 'never have this feeling' to 'always have this feeling')

- Do you have a feeling that you are in an unfamiliar situation and don't know what to do? (from 'very often' to 'very seldom or never')

The following items are examples that measure manageability:

- When something unpleasant happened in the past your tendency was: (from 'to eat yourself up about it' to 'to say "ok that's that, I have to live with it" and go on')

- When you do something that gives you a good feeling: (from 'it's certain that you'll go on feeling good' to 'it's certain that something will happen to spoil the feeling')

Meaningfulness is measured with items like these:

- Doing the things you do every day is: (from 'a source of deep pleasure and satisfaction' to 'a source of pain and boredom')

- When you think about your life, you very often: (from 'feel how good it is to be alive' to 'ask yourself why you exist at all') 
Comprehensibility, the cognitive dimension, refers to the extent to which one perceives internal and external stimuli as rationally understandable, and as information that is orderly, coherent, clear, structured rather than noise - that is, chaotic, disordered, random, unexpected, and unexplained (Antonovsky, 1987, p. 17). The ability to create structure out of chaos makes it easier for us to understand one's context and one's part in it, for example, one's role in the family or the workplace. A prerequisite to being able to cope with a stressful situation is that one can, to some extent, understand it. What one comprehends is easier to manage.

Manageability, the instrumental or behavioral dimension, defined as the degree to which one feels that there are resources at one's disposal that can be used to meet the requirements of the stimuli one is bombarded by Antonovsky (1987, p. 17). Formal resources include, for example, social services and care staff in public and private organizations. Informal resources include, for example, family, a circle of friends, colleagues, and significant others, in other words, people who are trusted and who can be relied on difficult situations. Coping also requires that one is motivated to solve the problems that cause stress, is willing to invest energy to solve the problem, and finds meaning in being able to manage the situation. This leads to the third dimension of the sense of coherence, meaningfulness.

Meaningfulness, the motivational dimension, refers to the extent to which one feels that life has emotional meaning, that at least some of the problems faced in life a face are worth commitment and dedication, and are seen as challenges rather than only as burdens (Antonovsky, 1987, p. 18). One needs to have a clear desire to resolve difficulties and willingness to invest energy to get through experiences of stress that have the potential to cause distress.

\section{The Validity and Reliability of the Sense of Coherence}

Face validity: The sense of coherence scales has been empirically tested in different cultures, both Western and cultures in Africa and Asia. Studies have been conducted on different samples: general populations, different professions, in persons with disabilities, different patient groups as well as in children, adolescents, adults, and elderly, in families, in organizations, and also on a societal level. A systematic research review shows that as of 2003, the SOC-29 and SOC-13 had been used in at least 33 different languages in 32 different countries (Eriksson \& Lindström, 2005). An update shows that another 16 languages can be added:
Albanian (Roth \& Ekblad, 2006), Croatian (Singer \& Brähler, 2007), Brazilian (Bonanato et al., 2009), Hungarian (Biro et al., 2010), Korean (Han et al., 2007), Lingala (Bantu language spoken in parts of Africa) (Pham et al., 2010), Persian, Swahili (Rohani et al., 2010) as well as local languages in Africa Afar, Bilein, Hidareb, Kunama people, Nara, Saho, Tigre, and Tigrinya (Almedom et al., 2007; Getnet \& Alem, 2019). An update per 2019 at least additional languages can be found: Portuguese (Encarnação et al., 2018) and Slovenia (Stern et al., 2019).

Since 2003, the SOC-29 and the SOC-13 have been used in further 13 countries (Eriksson, 2014): Eritrea (Almedom et al., 2007), Croatia (Pavicic Bosnjak et al., 2012), Hungary (Biro et al., 2010), India (Suraj \& Singh, 2011), Iran (Rohani et al., 2010), Italy (Sardu et al., 2012; Ciairano et al., 2010), Korea (Han et al., 2007), Kosovo, the Democratic Republic of Congo (Pham et al., 2010), Spain (Virues-Ortéga et al., 2007), Sudan (Abdelgadir et al., 2009), Taiwan (Tang \& Li, 2008), and Turkey (Öztekin \& Tezer, 2009). More recent research shows three additional countries: Austria (Mautner et al., 2014), Estonia (Höjdahl et al., 2015), and Malaysia (Rostami et al., 2014). An update per 2019 shows further expansion: Ethiopia (Getnet \& Alem, 2019), Ireland (Groarke et al., 2018), Portugal (Encarnação et al., 2018), and Slovenia (Stern et al., 2019).

In sum, the SOC questionnaires have been used in at least 51 different languages in at least 51 different countries around the world (Fig. 11.2).

The translation process: As shown above, SOC-13 has been translated and used in many countries and different populations. Translation of scales and questionnaires requires explicit attention since translation may influence validity (Naaldenberg et al., 2011). According to Fawcett (1997) and the Curitiba Statement on Health Promotion (Sotgiu et al., 2018), several translation techniques have to be used: calque, literal translation, transposition, modulation, reformulation, and adaptation. Transposition means rearranging a sentence's word sequence in order to satisfy grammatical rules; modulation is replacing original phrases with a set phrase, which has the same significance; reformulation is to express the same concept in a completely different manner; and, finally, adaption explains a concept in the source and target languages in a completely unique way, so it is appropriate to the culture of the recipients.

A critical term is the word "feelings." In English, the word "feeling" means both "something that you feel through the mind or the senses like hunger, sadness" and "the emotions of a person." A problem arose in the process of translation of SOC-13 from English to Italian. In Italian, two 


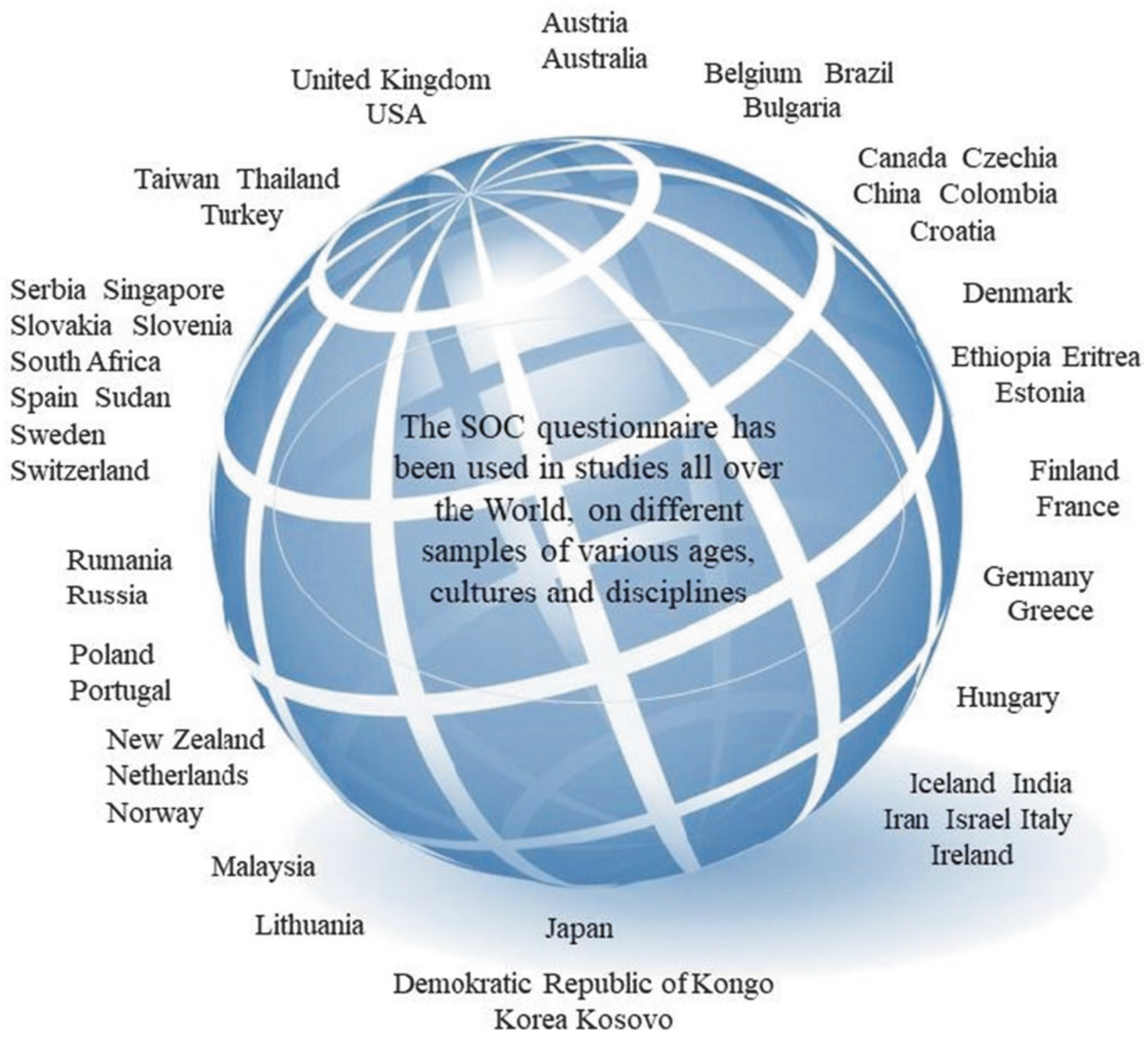

Fig. 11.2 The distribution of studies using the sense of coherence scale 1992-2019 in a global context @ Monica Eriksson 2017. (All Rights Reserved)

concepts are expressed, respectively, with the words "sensazione" and "emozione."

The translation of the question, "Many people - those with even a strong character - sometimes feel like sad sacks (losers) in certain situations. How often have you felt this way in the past?," revealed a minor difficulty of idiomatic equivalence. In the Italian version, it was necessary to eliminate the idiom "sad sacks" for which there is no corresponding expression. The significance of the question is still guaranteed by the translation of the word "losers."
Construct validity: The structure of the sense of coherence is complex. Recent research shows that the sense of coherence seems to be a multidimensional construct rather than a unidimensional as proposed by Antonovsky (1987), with all three dimensions continually interacting with each other and together to form a collective, overarching factor, sense of coherence. Following that, Antonovsky maintained that on theoretical grounds, one should avoid lifting out individual dimensions in order to examine them separately. 
Nevertheless, recent research has focused on the study of the structure and content of the sense of coherence. There are studies that support Antonovsky's idea of the sense of coherence as a general factor with three dimensions (Antonovsky, 1993; Drageset \& Haugan, 2015; Klepp et al., 2007; Rajesh et al., 2015; Söderhamn \& Holmgren, 2004; Söderhamn et al., 2015; Spadoti Dantas et al., 2014), but these dimensions do not fully fit with comprehensibility, manageability, and meaningfulness. Söderhamn et al. (2015) found evidence in a confirmatory factor analysis that confirmed the SOC-29 as one theoretical construct with three dimensions, comprehensibility, manageability, and meaningfulness. In a cross-sectional survey among Norwegian cognitively intact nursing home residents, Drageset and Haugan (2015) found that the three-factor model fit their data. Lajunen (2019) examined the psychometric properties and the cross-cultural impact of the SOC-13 questionnaire among Australian, Finnish, and Turkish young adults. The findings from all the three countries suggested that the first- and second-order three-factor models fit the data better than the single-factor model. Nor cultural differences in SOC scale scores were found.

Other models obtained with factorial analysis, although three-dimensional and with considerable explained variance, are not related to the traditional dimensions of the SOC. This is in agreement with previous research on SOC factorial dimension that showed different results not fitting with the dimensions of comprehensibility, manageability, and meaningfulness (Togari et al., 2008; Larsson \& Kallenberg, 1999).
A high correlation between item "Has it happened in the past that you were surprised by the behavior of people whom you thought you knew well?" and item "Has it happened that people whom you counted on disappointed you?" has been found in several studies (Naaldenberg et al., 2011; Sardu et al., 2012), and was explained by interviewees perceiving these questions as similar. Drageset and Haugan (2015) defined this correlation as "especially troublesome": the people whom we know well usually also embody the ones we trust or rely on, which is a central focus in OLQ3; you are not supposed to be disappointed by people you trust. Therefore, it seems theoretically reasonable that OLQ2 and OLQ3 share error variance. Nevertheless, including correlated error terms for this pair of items did not yield a good fit with the present data. Lerdal et al. (2017) found psychometric limitations of the 13-item SOC scale using Rasch analysis. Two items demonstrated poor fit, and once they were deleted from the scale, the remaining 11-item scale (SOC-11) demonstrated acceptable item fit. However, neither the SOC-13 nor the SOC-11 met the criteria for unidimensionality or personresponse validity. While both the SOC-13 and SOC-11 were able to distinguish three groups of SOC, none of the subscales could distinguish any such groups. Recent research suggests that the sense of coherence seems to be a multidimensional concept consisting of many different dimensions rather than a single factor (Eriksson \& Lindström, 2005; Feldt, 2007; Naaldenberg et al., 2011). Figure 11.3 shows the sense of coherence as a multidimensional construct.

Sandell et al. (1998) examined the sense of coherence instrument among a sample of Swedes and could not find

\section{SENSE OF COHERENCE}

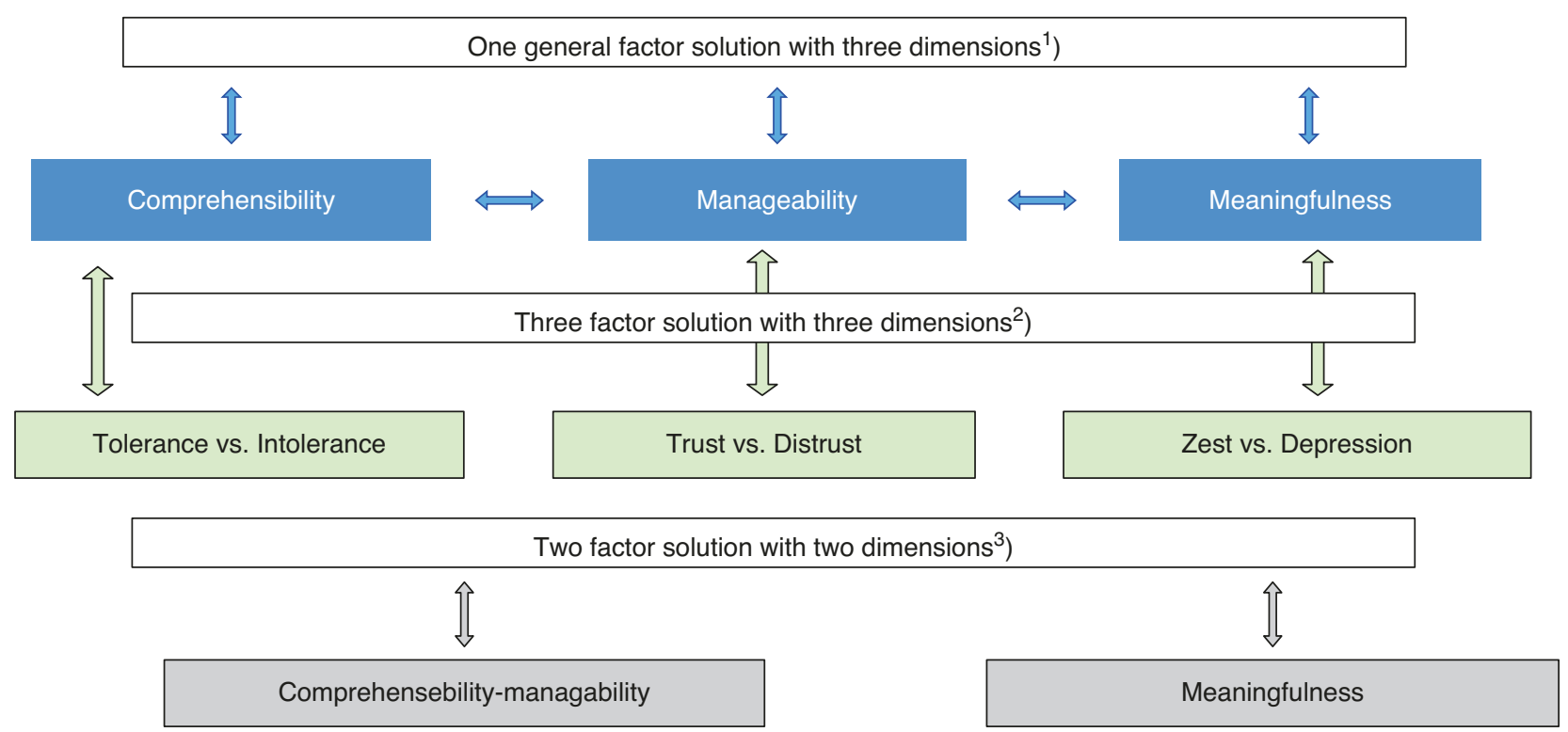

Fig. 11.3 The sense of coherence as a multidimensional construct. (1) Antonovsky, 1987, (2) Sandell et al., 1998, (3) Sakano \& Yajima, 2005 
support for a common factor, nor the three dimensions of comprehensibility, manageability, and meaningfulness. Three more or less stable dimensions emerged, where lust and depression were two extremes which could best be referred to the dimension of meaningfulness. Antonovsky's concept comprehensibility could in this study be seen in the form of tolerance versus intolerance. The third factor, manageability, was reflected by trust and distrust (Sandell et al., 1998, p. 701).

In the model reported by Larsson and Kallenberg (1999) in Sweden, the first factor appears to measure mainly anxiety and inner tension, although they partly also reflect one's ability to manage these emotions, the second factor covers comprehension regarding social perception, and the third factor appears to measure sense of personal meaningfulness and satisfaction. Also in the Sardinian general population, the model obtained with factorial analysis, although threedimensional and with considerable explained variance, is not related to the traditional dimensions of SOC represented in more than one factor (Sardu et al., 2012. The same model was substantially confirmed in samples of students and persons affected by chronic diseases.

Although a clear structure based on the three components was never obtained, three more or less stable dimensions emerged in most of the studies that have explored SOC-13 dimensions. The main factor normally involves most of the questions related to Antonovsky's comprehensibility component (items 6, 8, 9,11) but also items related to manageability (13 and sometimes 5). The Antonovsky's meaningfulness component (items 12, 1, 4, 7) is mainly represented in the second factor but also shows relevant correlations with the first one (in Sardinia all these items are combined with comprehensibility in the first factor). In the Sardinian study, question 10 (manageability dimension) does not show a stable pattern (Sardu et al., 2012). So one factor identified the comprehensibility component, and a second factor correlated very strongly with meaningfulness. The third factor was related to questions $\mathrm{B}$ and $\mathrm{C}$ that, as previously discussed, are part of different dimensions, yet are strongly correlated.

On the basis of the present findings, one may conclude that the factorial structure of the SOCS is sufficiently stable across different samples, although the emerging factors are not related to the traditional Antonovsky's dimensions of SOC. Sandell et al. (1998) conclude that these patterns are clouded by the fact that the items are indeed not "cleanly" referring to one or the other component, as Antonovsky endeavored (Table 11.1).

Consensual validity is a term that indicates the extent to which various scientists agree on the properties of an instrument (Cooper, 1998). The consensual validity is somewhat weak. While many researchers use either the SOC-29 or the SOC-13, there are also many different modified versions in use, with different numbers of questions and different possibilities of response options. Most of the modified versions have partially abandoned the original scale of $1-7$ points (but the wording of the questions is usually the same as in the SOC-29 and SOC-13). Results from a research review 1992 2003 showed that there were at least 15 different modified forms consisting of only 3 questions to 28 questions (Eriksson \& Lindström, 2005). This includes the particular version adapted for families (FSOC) (Antonovsky \& Sourani, 1988; Sagy \& Antonovsky, 1992), for children (Margalit \& Efrati, 1996), and a version for a school context (Nash, 2002). The Children's Orientation to Life Scale consists of 16 questions plus 3 distracters (Idan \& Margalit, 2014; Margalit \& Efrati, 1996). The response options follow a scale of $1-4$, where 4 indicates the highest degree of sense of coherence. There are also two variants of the FSOC, the original with 26 questions and a shorter version with 12 questions (Antonovsky \& Sourani, 1988; Sagy, 2008; Sagy \& Antonovsky, 1992). The questions are the same as in the original form but tailored to the child or a family context. Table 11.2 provides a summary of some of the other sense of coherence scales in the literature, demonstrating a range of items from 3 to 16, and intended for use by various sociodemographic groups.

Antonovsky (1979) originally described the sense of coherence as an individual property. He later widened the perspective (Antonovsky, 1987) with sense of coherence also conceived at the family level. Recent research shows that the sense of coherence concept and measurement also can be applied in organizations such as a workplace (Bauer \& Jenny, 2012; Bringsén, 2010; Bringsén et al., 2009; Forbech \& Hanson, 2013; Graeser, 2011; Mayer \& Krause, 2011; Mayer \& Boness, 2011; Nilsson et al., 2012; Orvik \& Axelsson, 2012; Vogt et al., 2013).

Research that examines and discusses salutogenesis and the sense of coherence at a societal level is sparse. BraunLewensohn and Sagy (2011) report findings from studies using an instrument adapted for the societal sense of coherence (Sense of Community Coherence), which contains seven questions describing how the individual experiences the society in terms of comprehensibility, manageability, and meaningfulness. Comprehensibility at the societal level addresses the experience of society as more or less organized in a way that makes life somewhat predictable, that the structure of society can be more or less understood, and that society is perceived as more or less safe and secure. Manageability is a state in which the individual experiences a society with resources that support individuals, for example, in emergencies or critical situations. Societal support includes, for example, programs to support young people's mental health and initiatives to create conditions so that people from different generations can meet each other. Meaningfulness refers to the experience that society supports people to experience 


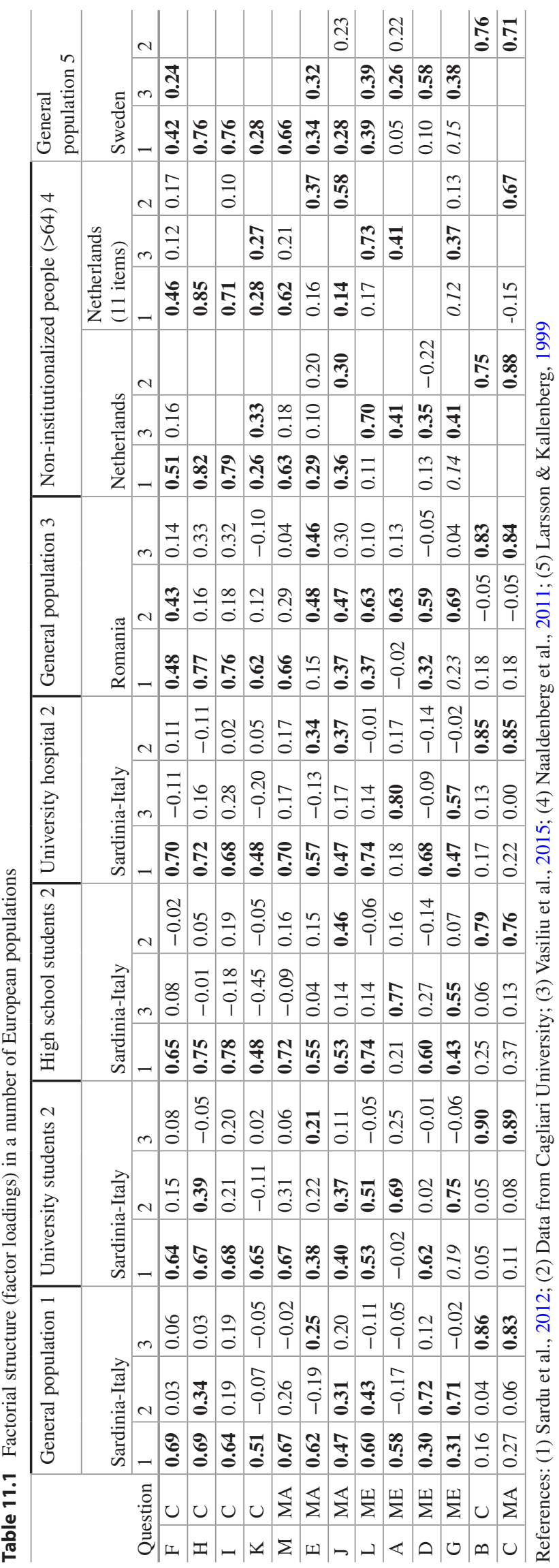



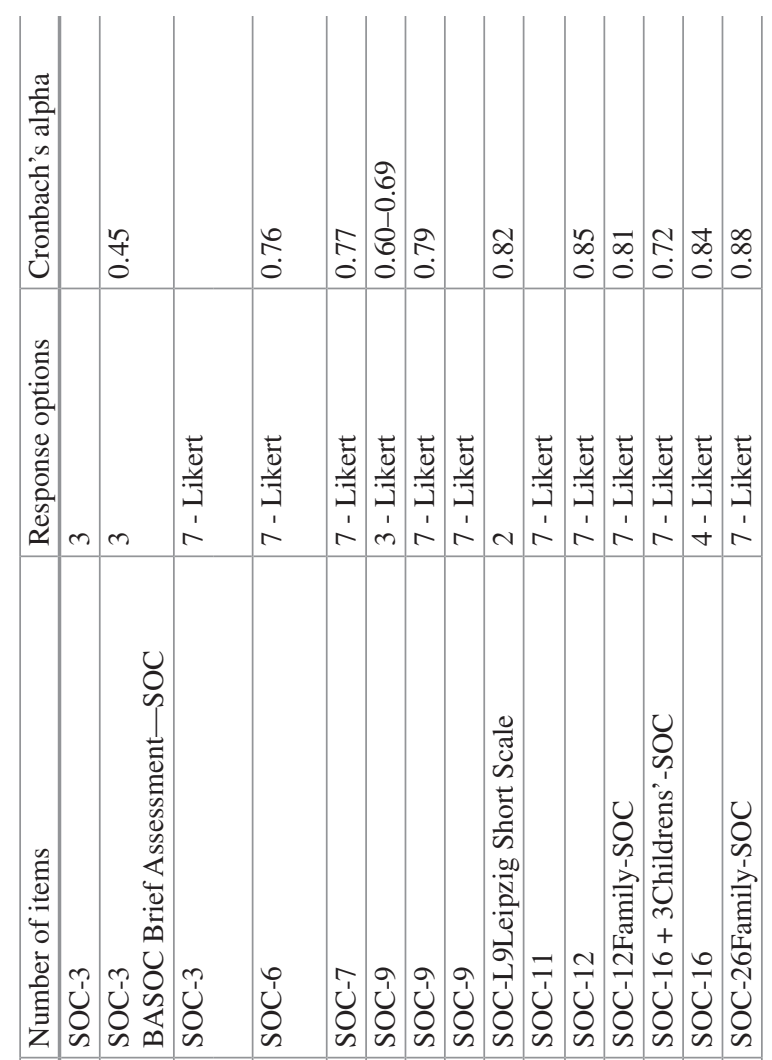

z榇誉

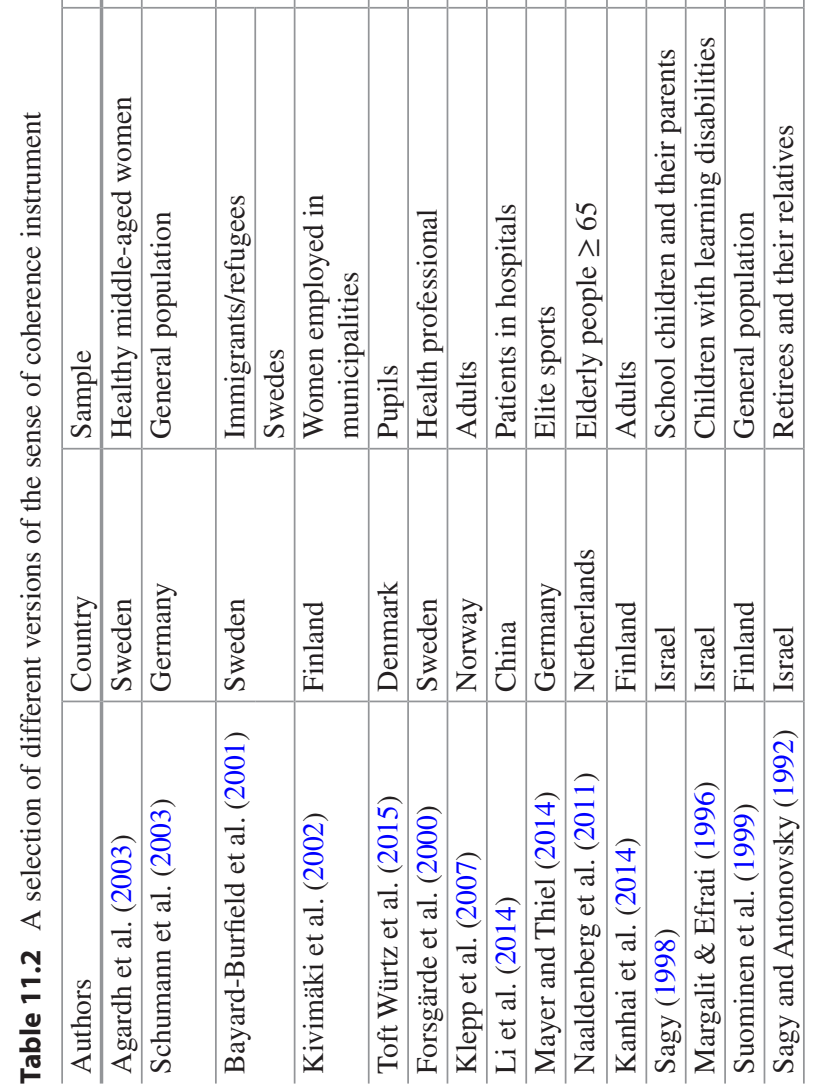


fulfillment, to develop their abilities, and to feel satisfied with life (Braun-Lewensohn \& Sagy, 2011, p. 535).

The relevance of salutogenesis and the sense of coherence to the building of healthy public policy has also been a focus of theorizing and research (Eriksson et al., 2007; Lindström $\&$ Eriksson, 2009). To develop a social policy based on the salutogenic framework means to identify resources for health and welfare of the society, in the past as well as in the present, including risks of illnesses, and how this knowledge and the most effective measures can be used to resolve the current challenges. The core of such policy is to create coherence and synergies, from individuals to groups and organizations in the local community, and finally to the whole of society (Eriksson \& Lindström, 2014; Lindström \& Eriksson, 2009).

Criterion validity: Eriksson and Lindström (2005) present information about the relation between the SOC-29 and other instruments measuring health, perceived self, stressors, quality of life, well-being, attitudes, and behaviors. The correlation with health ranges in general from slight to good, using instruments such as the General Health Questionnaire, the Health Index, the Hopkin's Symptom Checklist, and the Mental Health Inventory, with such health measures explaining up to $66 \%$ of the variance in the SOC-29. There seems to be an overlap between the sense of coherence and the Big Five (Kase et al., 2018). Neuroticism was here negatively correlated, and extraversion was positively correlated with comprehensibility $(r-0.47,0.35)$, manageability $(r-0.44,0.26)$, and meaningfulness $(r-0.28,0.30)$. These correlations were strong, and the overlap between the two scales was about 36 percent. Also, there are a number of studies on the relation between SOC and quality of life and wellbeing. In general, they show that a high SOC is related to a high quality of life Eriksson and Lindström (2005).

Predictive validity: The ability of an instrument to predict how, for example, health develops in the future is called predictive validity (Abramson \& Abramson, 1999). The predictive validity of the sense of coherence questionnaire seems to be relatively good, based on a review of longitudinal studies (Eriksson \& Lindström, 2005). There are studies that support predictive ability (Lundman et al., 2010; Luutonen et al., 2011; Poppius et al., 2006; Surtees et al., 2003), whereas other studies have not done so (Norekvål et al., 2010). It seems that the time for follow-up is an important factor for the predictive ability of the instrument. The results of a study among elderly persons, the Umeå 85+ study, show that the sense of coherence predicted mortality at 1-year follow-up, but not at follow-up after 4 years (Lundman et al., 2010).
Reliability: SOC-29 test-retest correlations range from 0.69 to 0.78 (1 year), 0.64 (3 years), 0:42 to 00:45 (4 years), 0:59 to 0.67 (5 years), and finally 0:54 after the 10-year follow-up (Eriksson \& Lindström, 2005). More recent research provides support for the stability over time, in 1- to 3-year perspective (Lindblad, Sandelin, Petersson et al., 2016). The internal consistency measured by Cronbach's alpha ranges from 0.70 to 0.95 using SOC-29 (124 studies) and 0.70 to 0.92 (127 studies) using SOC-13 (Eriksson \& Lindström, 2005 , p. 463). The sense of coherence scale shows high internal consistency overall. However, there are other results reported. Among Swedish nurses working at hospitals, the internal consistency, measured by Cronbach's alpha, was as low as 0.63 (Eriksson et al., 2019). An inter-item-correlation test indicated that item 5 "Do you have the feeling that you're being treated unfairly?" and item 6 "Do you have the feeling that you are in an unfamiliar situation and don't know what to do?" decreased the internal consistency.

\section{Critique of the SOC-29 and SOC-13}

One indirect form of criticism has practical roots: as mentioned earlier, various senses of coherence measures have been developed that are shorter than even the SOC-13, as short as just three items. This reflects the reality that in many health survey applications, questionnaires must be very short. More directly, the SOC-29 and SOC-13 have been criticized based on supposed shortcomings in the instruments' psychometric properties (Korotkov, 1993; Larsson \& Kallenberg, 1999; Schnyder et al., 2000). It is also asserted that the sense of coherence concept does not deal adequately with emotional aspects of life experience (Flannery \& Flannery, 1990; Flensborg-Madsen et al., 2006c; Korotkov, 1993; Korotkov \& Hannah, 1994). Inconsistent evidence about the lability/stability of the sense of coherence over the life course has also been noted by critics (Geyer, 1997). Criticism of salutogenesis generally includes implicit doubt about efforts to measure the sense of coherence via any means (Bengel et al., 1999; Kumlin, 1998). The leveling of such criticism is welcome as part of the healthy evolution of a "living" theory or model, and responses to the critics are published (Eriksson, 2007; Lindström \& Eriksson, 2010).

In the limits of this chapter, we focus on just the critical ideas of Flensborg-Madsen et al. (2005a). The critique stems from their conclusion that the SOC-29 and SOC-13 are only moderately to weakly related to various measures of physical health (Flensborg-Madsen et al., 2005a), leading them to construct and test a new measure of the sense of coherence, intended to overcome limitations in the SOC-29 and SOC-13 (Flensborg-Madsen et al., 2006a, 2006b). Their critique can be summarized in this way: 
- Antonovsky presumed that one's internal and external environment has to be predictable in order for a person to have a high sense of coherence.

- Predictability should not be included in conceptualizing and measuring the sense of coherence, because lack of predictability is not necessarily unhealthy.

- Instead, unpredictability is what makes life matter in the first place; it can provide a state of initiative, energy, and positive attitudes.

Since the SOC-29 includes several items that have to do with predictability, Flensborg-Madsen et al. (2005b) regard the instrument as flawed and they developed an alternative 9-item measure that excluded the concept of predictability, but that otherwise was purportedly built, as they write, on the same idea, theory, and conceptualization used by Antonovsky (Flensborg-Madsen et al., 2006a, 2006b).

Their conclusion about a weak association between the SOC-29 and SOC-13 and physical health is based on a review of about 50 studies (2005a). They categorize the health instruments in the reviewed studies as having foci on physical health, biological measures, psychological measures, health measures incorporating psychological aspects, stress, and behavioral aspects. They conclude that the SOC scales are unable to explain health that is measured only in physical terms (Flensborg-Madsen et al., 2005a, p. 665). As a solution, Flensborg-Madsen et al. (2006c) propose the concept of "emotional coherence" in relation to physical health and "mental coherence" in relation to psychological health. This is supported by Endler et al. (2008).

Such fragmentation of the concept of the sense of coherence into physical and mental components breaks significantly from Antonovsky's fundamental notion of an "orientation to life" $(1979,1987)$. Such fragmentation also reinforces the physical health/mental health divide in modern health care (and in the public's imagination), which has been challenged vigorously (WHO, 2001).

We move on to the issue of excluding predictability in the sense of coherence measurement; to do so is to depart emphatically from "the same idea, theory and conceptualization" used by Antonovsky, who wrote:

From the time of birth, or even earlier, we constantly go through situations of challenge and response, stress, tension, and resolution. The more these experiences are characterized by consistency, participation in shaping outcome, and an underload-overload balance of stimuli, the more we begin to see the world as being coherent and predictable. When, however, one's experiences all tend to be predictable, one is inevitably due for unpleasant surprises that cannot be handled, and one's sense of coherence is weakened accordingly. Paradoxically, then, a measure of unpredictable experiences-which call forth hitherto unknown resources-is essential for a strong sense of coherence. One then learns to expect some measure of the unexpected. When there is little or no predictability, there is not much one can do except seek to hide until the storm (of life) is over, hoping not to be noticed. Or else one strikes out blindly and at random until exhaustion sets in. No defense mechanisms can be adequate. We must note an implicit assumption here. If a strong sense of coherence is to develop, one's experiences must be not only by and large predictable but also by and large rewarding, yet with some measure of frustration and punishment. (Antonovsky, 1979, p. 187)

As this extended passage makes clear, reasonable predictability functions inextricably with many other aspects of experience to shape the sense of coherence.

\section{Sense of Coherence Develops Over Time}

According to Antonovsky (1987), sense of coherence develops until the age of about 30 years. After that, the sense of coherence was estimated to remain relatively stable until retirement, after which a decrease was expected. This assumption finds no support in subsequent empirical research. The sense of coherence seems to be relatively stable over time, but not as stable as Antonovsky assumed. Research shows that sense of coherence develops over the entire life cycle and increases with age (Feldt, Lintula, et al., 2007; Feldt, Metsäpelto, et al., 2007; Nilsson et al., 2010). Nilsson and co-authors were able to demonstrate on a sample of 43,500 Swedish respondents, aged 18-85 years, that sense of coherence increases with age in both men and women. Support for a corresponding development of the sense of coherence over time could also be seen in a longitudinal study of more than 18,000 Finns, in the Health and Social Support Study, where the sense of coherence continuously increased with age. A strong sense of coherence initially appears to determine its development over time (Feldt et al., 2011). There is a lack of longitudinal studies with long-term follow-up. The most extended follow-up is that of 13 years (Hakanen et al., 2007). Table 11.3 shows findings from longitudinal studies with different follow-up periods.

Table 11.3 The development of the sense of coherence over time, based on a sample of longitudinal studies

\begin{tabular}{l|l|l|l}
\hline $1 \rightarrow 2$ year & 0.8 points & SOC-13 & Bergman et al. (2012) \\
\hline $1 \rightarrow 3$ year & $\begin{array}{l}14.2 \\
\text { points }\end{array}$ & SOC-28 & $\begin{array}{l}\text { Kuuppelomäki and } \\
\text { Utriainen }(2003)\end{array}$ \\
\hline $1 \rightarrow 3$ year & 0.1 points & SOC-13 & Honkinen et al. $(2008)$ \\
\hline $1 \rightarrow 5$ year & 1.6 points & SOC-13 & Volanen et al. $(2007)$ \\
\hline $1 \rightarrow 5$ year & 1.8 points & SOC-13 & Bergman et al. $(2012)$ \\
\hline $1 \rightarrow 5$ year & 3.6 points & SOC-13 & Lövheim et al. $(2013)$ \\
\hline $1 \rightarrow 9$ year & 0.1 points & SOC-13 & Luutonen et al. $(2011)$ \\
\hline $1 \rightarrow 10$ year & 2.7 points & SOC-13 & Kalimo et al. $(2003)$ \\
\hline $1 \rightarrow 12$ year & 0.3 points & SOC-29 & $\begin{array}{l}\text { Holmberg and Thelin } \\
\text { (2010) }\end{array}$ \\
\hline $1 \rightarrow 13$ year & 0.4 points & SOC-13 & Hakanen et al. (2007) \\
\hline
\end{tabular}



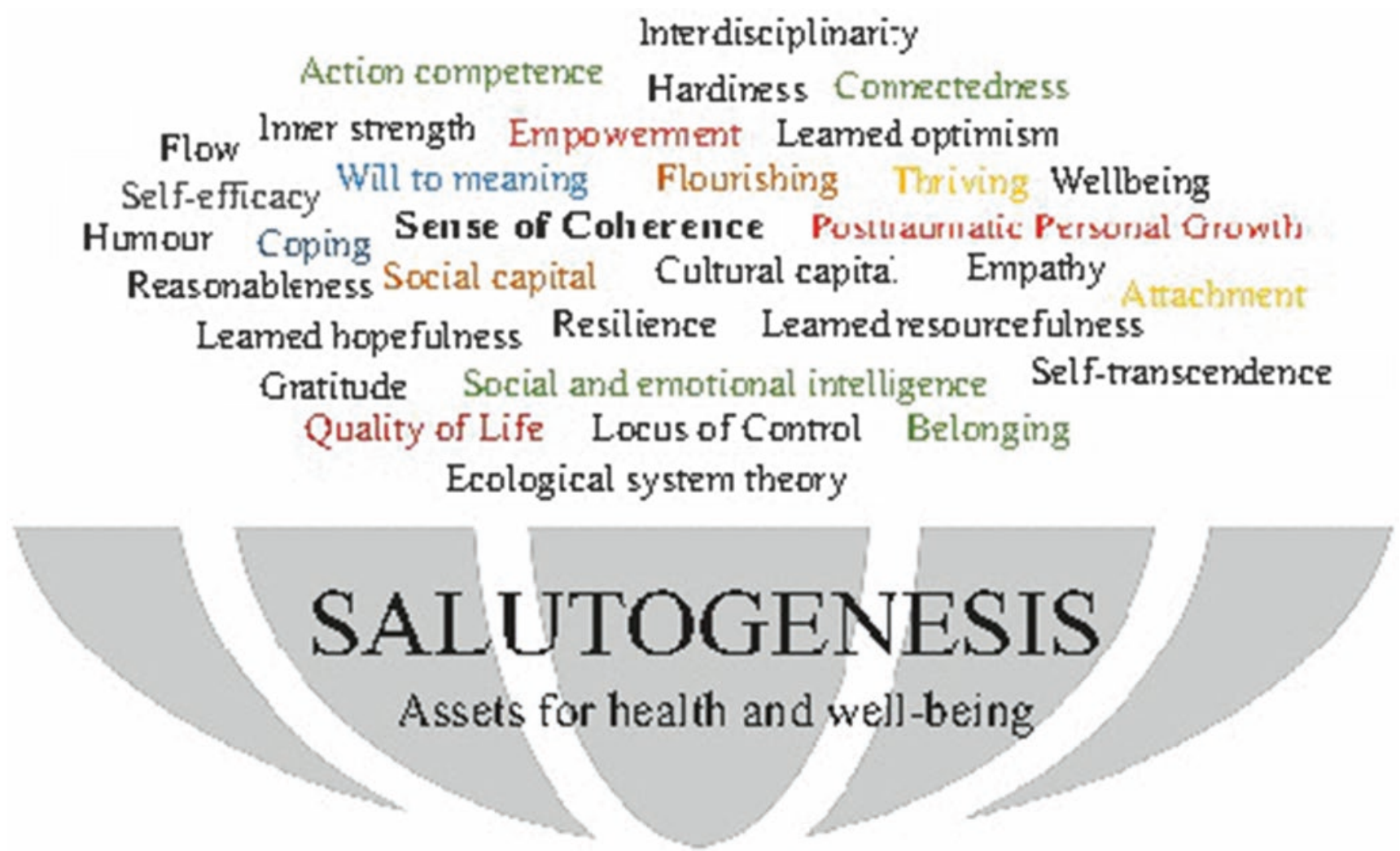

Fig. 11.4 The salutogenic umbrella, salutogenesis as an umbrella concept @ Monica Eriksson 2017. (All rights reserved)

\section{Salutogenesis Is More than the Measurement of the Sense of Coherence}

Salutogenesis, focusing on health and people's resources, is something more than the measurement of the sense of coherence. Today, we can talk about salutogenesis as an umbrella concept with many different theories and concepts with salutogenic elements and dimensions (Lindström \& Eriksson, 2010). There is extensive research that focuses on the resources of individuals, groups, and communities. All this and more can be accommodated under the common umbrella. Figure 11.4 shows some related concepts to the sense of coherence collected under an umbrella.

\section{References}

Abdelgadir, M., Shebeika, W., Eltom, M., Berne, C., \& Wikblad, K. (2009). Health related quality of life and sense of coherence in Sudanese diabetic subjects with lower limb amputation. Tohoku Journal of Experimental Medicine, 217, 45-50.

Abramson, J. H., \& Abramson, Z. H. (1999). Survey methods in community medicine. Epidemiological research programme evaluation clinical trials (5th ed.). Churchill Livingstone.
Agardh, E. E., Ahlbom, A., Andersson, T., et al. (2003). Work stress and low sense of coherence is associated with type 2 diabetes in middleaged Swedish women. Diabetes Care, 26(3), 719-724.

Almedom, A. M., Tesfamichael, B., Mohammed, Z. S., Mascie-Taylor, C. G. N., \& Alemu, Z. (2007). Use of "Sense of Coherence (SOC)" scale to measure resilience in Eritrea: Interrogating both the data and the scale. Journal of Biosocial Science, 39(1), 91-107.

Antonovsky, A. (1987). Unraveling the mystery of health. How people manage stress and stay well. Jossey-Bass Publishers.

Antonovsky, A. (1993). The salutogenic approach to aging. Lecture held in Berkeley, January 21, 1993.

Antonovsky, A. (1979). Health, Stress and Coping: New Perspectives on Mental and Physical Well-Being. San Francisco: Jossey-Bass.

Antonovsky, A., \& Sourani, T. (1988). Family sense of coherence and family adaptation. Journal of Marriage and Family, 50, 79-92.

Bauer, G., \& Jenny, G. J. (2012). Moving towards positive organizational health: Challenges and a proposal for a research model of organizational health development. In J. Houdmondt, S. Leka, \& R. R. Sinclair (Eds.), Contemporary occupational health psychology: Global perspectives on research and practice (Vol. 2). Wiley-Blackwell.

Bayard-Burfield, L., Sundquist, J., \& Johansson, S.-E. (2001). Ethnicity, self-reported psychiatric illness, and intake of psychotropic drugs in five ethnic groups in Sweden. Journal of Epidemiology and Community Health, 55, 657-664.

Bengel, J., Strittmatter, R., \& Willman, H. (1999). What keeps people healthy? The current state of discussion and the relevance of Antonovsky's salutogenic model of health. Federal Centre for Health Education (FCHE). 
Bergman, E., Årestedt, K., Fridlund, B., Karlsson, J.-E., \& Malm, D. (2012). The impact of comprehensibility and sense of coherence in the recovery of patients with myocardial infarction: A long-term follow-up study. European Journal of Cardiovascular Nursing, 11(3), 276-283.

Biro, E., Balajti, I., Adany, R., \& Kosa, K. (2010). Determinants of mental well-being in medical students. Social Psychiatry and Psychiatric Epidemiology, 45, 253-258.

Bonanato, K., Paiva, S. M., Pordeus, I. A., Ramos-Jorge, M. L., Barbabela, D., \& Allison, P. J. (2009). Relationship between mothers' sense of coherence and oral health status of preschool children. Caries Research, 43, 103-109.

Braun-Lewensohn, O., \& Sagy, S. (2011). Salutogenesis and culture: Personal and community sense of coherence among adolescents belonging to three different cultural groups. International Review of Psychiatry, 23(6), 533-541.

Bringsén, Å. (2010). Taking care of others-What's in it for us? Exploring workplace-related health from a salutogenic perspective in a nursing context. Doctoral thesis. Lund: Lund University.

Bringsén, Å., Andersson, I. H., \& Ejlertsson, G. (2009). Development and quality analysis of the Salutogenic Health Indicator Scale (SHIS). Scandinavian Journal of Public Health, 37(1), 13-19.

Ciairano, S., Rabaglietti, E., Roggero, A., \& Callari, T. C. (2010). Life satisfaction, sense of coherence and job precariousness in Italian young adults. Journal of Adult Development, 17, 177-189.

Cooper, H. (1998). Synthesizing research. A guide for literature review. Sage.

Drageset, J., \& Haugan, G. (2015). Psychometric properties of the Orientation to Life Questionnaire in nursing home residents. Scandinavian Journal of Caring Sciences. https://doi.org/10.1111/ scs. 12271

Encarnação, P., Oliveira, C. C., \& Martins, T. (2018). Psychometric properties of the suffering assessment questionnaire in adults with chronic diseases or life-threatening illness. Scandinavian Journal of Caring Sciences, 32(4), 1279-1287.

Endler, C. P., Haug, T. M., \& Spranger, H. (2008). Sense of Coherence and physical health. A "Copenhagen interpretation" of Antonovsky's SOC concept. The Scientific World Journal, 8, 451-453.

Eriksson, M. (2007). Unravelling the Mystery of Salutogenesis. The evidence base of the salutogenic research as measured by Antonovsky's Sense of Coherence Scale. [Doctoral thesis]. Åbo Akademi University, Department of Social Policy. Folkhälsan Research Centre, Health Promotion Research Programme, Research Report 2007:1. Turku: Folkhälsan.

Eriksson, M. (2014). The salutogenic framework for health promotion and disease prevention. In D. I. Mostofsky (Ed.), The handbook of behavioral medicine. Hoboken.

Eriksson, M., Kerekes, N., Brink, P., Pennbrant, S., \& Nunstedt, H. (2019). The level of sense of coherence among Swedish nursing staff. Journal of Advanced Nursing, 00, 1-7. https://doi.org/10.1111/ jan. 14137

Eriksson, M., \& Lindström, B. (2005). Validity of Antonovsky's sense of coherence scale-A systematic review. Journal of Epidemiology \& Community Health, 59(6), 460-466.

Eriksson, M., \& Lindström, B. (2014). The salutogenic framework for well-being: Implications for public policy. In T. J. Hämäläinen \& J. Michaelson (Eds.), Well-being and beyond. Broadening the public and policy discourse (pp. 68-97). Edward Elgar.

Eriksson, M., Lindström, B., \& Lilja, J. (2007). A sense of coherence and health. Åland, a special case. Journal of Epidemiology and Community Health, 61(8), 684-688.

Fawcett, P. (1997). Translation and language: Linguistic theories explained. St Jerome Publishing.

Feldt, T., Metsäpelto, R.-L., Kinnunen, U., \& Pulkkinen, L. (2007). Sense of coherence and five-factor approach to personality. Conceptual relationships. European Psychologist, 12(3), 165-172.
Feldt, T., Leskinen, E., Koskenvuo, M., Suominen, S., Vahtera, J., \& Kivimäki, M. (2011). Development of sense of coherence in adulthood: A person-centered approach. The population-based HeSSup cohort study. Quality of Life Research, 20(1), 69-79.

Feldt, T., Lintula, H., Suominen, S., Koskenvuo, M., Vahtera, J., \& Kivimäki, M. (2007). Structural validity and temporal stability of the 13-item sense of coherence scale: Prospective evidence from the population-based HeSSup study. Quality of Life Research, 16(3), 483-493.

Flannery, R. B., \& Flannery, G. J. (1990). Sense of coherence, life stress, and psychological distress: A prospective methodological inquiry. Journal of Clinical Psychology, 46(4), 415-420.

Flensborg-Madsen, T., Ventegodt, S., \& Merrick, J. (2005a). Sense of coherence and physical health. A review of previous findings. The Scientific World Journal, 5, 665-673.

Flensborg-Madsen, T., Ventegodt, S., \& Merrick, J. (2005b). Why is Antonovsky's sense of coherence not correlated to physical health? Analyzing Antonovsky's 29-item Sense of Coherence Scale (SOC29). The Scientific World Journal, 5, 767-776.

Flensborg-Madsen, T., Ventegodt, S., \& Merrick, J. (2006a). Sense of coherence and physical health. Testing Antonovsky's theory. The Scientific World Journal, 6, 2212-2219.

Flensborg-Madsen, T., Ventegodt, S., \& Merrick, J. (2006b). Sense of coherence and physical health. A cross-sectional study using a new scale (SOC II). The Scientific World Journal, 6, 2200-2211.

Flensborg-Madsen, T., Ventegodt, S., \& Merrick, J. (2006c). Sense of Coherence and physical health. The Emotional Sense of Coherence (SOC-E) was found to be the best-known predictor of physical health. The Scientific World Journal, 6, 2147-2157.

Forbech, V. H., \& Hanson, A. L. (2013). Salutogenic presence supports a health-promoting work life. Journal of Social Medicine, 6, 890-901.

Forsgärde, M., Westman, B., \& Nygren, L. (2000). Ethical discussion groups as an intervention to improve the climate in inter-professional work with the elderly and disabled. Journal of Interprofessional Care, 14(4), 351-361.

Getnet, B. \& Alem, A. (2019). Construct calidity and factor structure of sense of coherence (SoC-13) scale as a measure of resilicence in Eritrean refugees living in Ethopia. Conflict and Health, 13, 3.

Geyer, S. (1997). Some conceptual considerations on the sense of coherence. Social Science \& Medicine, 44(12), 1771-1779.

Government Offices of Sweden. (2006). The convention of the rights of the child. [Elektronic]. Retrieved December 30, 2015, from http:// www.regeringen.se/content/1/c6/04/09/98/b8de24c7.pdf

Government Offices of Sweden. (2008). UN:s convention on the Rights of Persons with disabilities. [Elektronic]. Retrieved December 30, 2015, from http://www.regeringen.se/content/1/ c6/10/19/18/516a2b36.pdf

Government Offices of Sweden. (2011). United Nations. The Universal Declaration of Human Rights. [Elektronic]. Retrieved December 30, 2015, from http://www.regeringen.se/content/1/ c6/18/37/41/3014596d.pdf

Graeser, S. (2011). Salutogenic factors for mental health promotion in work settings and organizations. International Review of Psychiatry, 23(6), 508-515.

Groarke, A. M., Curtis, R., Walsh, D. M. J., \& Sullivan, F. (2018). What predicts emotional response in men awaiting prostate biopsy? BMC Urology, 18, 27. https://doi.org/10.1186/s12894-018-0340-9

Hakanen, J. J., Feldt, T., \& Leskinen, E. (2007). Change and stability of sense of coherence in adulthood: Longitudinal evidence from the Healthy Child Study. Journal of Research in Personality, 41, 602-617.

Han, K., Lee, P., Park, E., Park, Y., Kim, J., \& Kangh, H. (2007). Family functioning and mental illness a Korean correlational study. Asian Journal of Nursing, 10, 129-136. 
Holmefur, M., Sundberg, K., Wettergren, L., \& Langius-Eklöf, A. (2015). Measurement properties of the 13-item sense of coherence scale using Rasch analysis. Quality of Life Research, 24, 1455-1463.

Höjdahl, T., Magnus, J. H., Mdala, I., Hagen, R., \& Langeland, E. (2015). Emotional distress and sense of coherence in women completing a motivational program in five countries. A prospective study. International Journal of Prisoner Health, 11(3), 169-182.

Holmberg, S., \& Thelin, A. G. (2010). Predictors of sick leave owing to neck or low back pain: A 12-year longitudinal cohort study in a rural male population. Annals of Agricultural and Environmental Medicine, 17(2), 251-257.

Honkinen, P. L., Suominen, S., Helenius, H., Aromaa, M., Rautava, P., Sourander, A., et al. (2008). Stability of the sense of coherence in adolescence. International Journal of Adolescent Medicine and Health, 14(4), 587-600.

Idan, O., \& Margalit, M. (2014). Socioemotional self-perceptions, family climate, and hopeful thinking among students with learning disabilities and typically achieving students from the same classes. Journal of Learning Disabilities, 47(2), 136-152.

Kanhai, J., Harrison, V. E., \& Suominen, A. L. (2014). Sense of coherence and incidence of periodontal disease in adults. Journal of Clinical Periodontology, 41, 760-765.

Kalimo, R., Pahkin, K., Mutanen, P., \& Toppinen-Tanner, S. (2003). Staying well or burning out at work: Work characteristics and personal resources as long-term predictors. Work \& Stress, 17(2), $109-122$.

Kase, T., Ueno, Y., \& Oishi, K. (2018). The overlap of sense of coherence and the Big Five personality traits: A confirmatory study. Health Psychology Open, 1-4. https://doi.org/10.1177/2055102918810654

Kivimäki, M., Elovainio, M., Vahtera, J., et al. (2002). Sense of coherence as a mediator between hostility and health. Seven-year prospective study on female employees. Journal of Psychosomatic Research, 52, 239-247.

Klepp, O. M., Mastekaasa, A., Sørensen, T., Sandanger, I., \& Kleiner, R. (2007). Structure analysis of Antonovsky's sense of coherence from an epidemiological mental health survey with a brief nineitem sense of coherence scale. International Journal of Methods in Psychiatric Research, 16(1), 11-22.

Korotkov, D. (1993). An assessment of the (short-form) sense of coherence personality measure: Issues of validity and well-being. Personal and Individual Differences, 14(4), 575-583.

Korotkov, D., \& Hannah, E. (1994). Extraversion and emotionality as proposed superordinate stress moderators: A prospective analysis. Personal and Individual Differences, 16(5), 787-792.

Kumlin, T. (1998). Sense of coherence in theory, empiri and criticism. [In Swedish]. (Vol. 9). Stockholm: The Swedish Research Council.

Kuuppelomäki, M., \& Utriainen, P. (2003). A 3 year follow-up study of health care students' sense of coherence and related smoking, drinking and physical exercise factors. International Journal of Nursing Studies, 40(4), 383-388.

Lajunen, T. (2019). Cross-Cultural Evaluation of Antonovsky's Orientation to Life Questionnaire: Comparison Between Australian, Finnish, and Turkish Young Adults. Psychological Reports, 122(2), 731-747.

Larsson, G., \& Kallenberg, K. (1999). Dimensional analysis of sense of coherence using structural equation modelling. European Journal of Personality, 13, 51-61.

Lerdal, A., Opheim, R., Gay, C. L., Moum, B., Fagermoen, M. S., \& Kottorp, A. (2017). Psychometric limitations of the 13-item Sense of Coherence Scale assessed by Rasch analysis. BMC Psychology, 5(1), 18. https://doi.org/10.1186/s40359-017-0187-y

Li, W., Leonhart, R., Schaefert, R., et al. (2014). Sense of coherence contributes to physical and mental health in general hospital patients in China. Psychology, Health \& Medicine. https://doi.org/10.1080/ 13548506.2014.952644

Lindblad, C., Sandelin, K., Petersson, L.-M., Rohani, C. \& LangiusEklöf, A. (2016). Stability of the 13 -item sense of coherence (SOC) scale: a longitudinal prospective study in women treated for breast cancer. Quaility of Life Research, 25, 753-60.
Lindström, B., \& Eriksson, M. (2009). The salutogenic approach to the making of HiAP/healthy public policy: Illustrated by a case study. Global Health Promotion, 16(1), 17-28.

Lindström, B., \& Eriksson, M. (2010). The Hitchhiker's Guide to Salutogenesis. Salutogenic pathways to health promotion. Folkhälsan and IUHPE Global Working Group on Salutogenesis.

Lövheim, H., Graneheim, U. H., Jonsén, E., Strandberg, G., \& Lundman, B. (2013). Changes in sense of coherence in old age-A 5 -year follow-up of the Umeå 85+ study. Scandinavian Journal of Caring Sciences, 27, 13-19.

Lundman, B., Forsberg, K. A., Jonsén, E., Gustafson, Y., Olofsson, K., Strandberg, G., et al. (2010). Sense of coherence (SOC) related to health and mortality among the very old: The Umeå 85+ study. Archives of Gerontology and Geriatrics, 51(3), 329-332.

Luutonen, S., Sohlman, B., Salokangas, R. K. R., Lehtinen, V., \& Dowrick, C. (2011). Weak sense of coherence predicts depression: 1-year and 9-year follow-ups of the Finnish Outcomes of Depression International Network (ODIN) sample. Journal of Mental Health, 20(1), 43-51.

Margalit, M., \& Efrati, M. (1996). Loneliness, coherence and companionship among children with learning disorder. Educational Psychology, 16(1), 69-80.

Mautner, E., Ashida, C., Greimel, E., Lang, U., Kolman, C., Aalton, D., \& Inoue, W. (2014). Are there differences in the health outcomes of mothers in Europe and East-Asia? A cross-cultural health survey. BioMed Research International. https://doi. org/10.1155/2014/856543

Mayer, C. H., \& Boness, C. (2011). Concepts of health and Wellbeing in managers. An organizational study. International Journal of Qualitative Studies on Health and Well-being, 6. https://doi. org/10.3402/qhw.v3406i3404.7143

Mayer, C.-H., \& Krause, C. (2011). Promoting mental health and salutogenesis in transcultural organizational and work contexts. International Review of Psychiatry, 23(6), 495-500.

Mayer, J., \& Thiel, A. (2014). Health in elite sports from a salutogenic perspective: Athletes' sense of coherence. PLOS One, 9(7), 1-11.

Naaldenberg, J., Tobi, H., van den Esker, F., \& Vaandrager, L. (2011). Psychometric properties of the OLQ-13 scale to measure Sense of Coherence in a community-dwelling older population. Health and Quality of Life Outcomes, 23(9), 37. https://doi. org/10.1186/1477-7525-9-37

Nash, J. K. (2002). Neighborhood effects on sense of school coherence and educational behavior in students at risk of school failure. Children \& Schools, 24(2), 73-89.

Nilsson, P., Andersson, I. H., Ejlertsson, G., \& Troein, M. (2012). Workplace health resources based on sense of coherence theory. International Journal of Workplace Health Management, 5(3), 156-167.

Nilsson, K. W., Leppert, J., Simonsson, B., \& Starrin, B. (2010). Sense of coherence and psychological well-being: Improvement with age. Journal of Epidemiology and Community Health, 64(4), 347-352.

Norekvål, T. M., Fridlund, B., Rokne, B., Segadal, L., Wentzel-Larsen, T., \& Nordrehaug, J. E. (2010). Patient-reported outcomes as predictors of 10-year survival in women after acute myocardial infarction. Health and Quality of Life Outcomes, 8, 140.

Orvik, A., \& Axelsson, R. (2012). Organizational health in health organizations: Towards a conceptualization. Scandinavian Journal of Caring Sciences, 26(4), 796-802.

Öztekin, C., \& Tezer, E. (2009). The role of sense of coherence and physical activity in positive and negative affect of Turkish adolescents. Adolescence, 44, 421-432.

Pavicic Bosnjak, A., Rumboldt, M., Stanojevic, M., \& Dennis, C. L. (2012). Psychometric assessment of the Croatian version of the breastfeeding self-efficacy scale-short form. Journal of Human Lactation, 28(4), 565-569.

Pham, P. N., Vink, P., Kinkodi, D. K., \& Weinstein, H. M. (2010). Sense of coherence and its association with exposure to traumatic events, posttraumatic stress disorder, and depression in the eastern Democratic Republic of Congo. Journal of Traumatic Stress, 23, 313-321. 
Poppius, E., Virkkunen, H., Hakama, M., \& Tenkanen, L. (2006). The sense of coherence and incidence of cancer - role of follow-up time and age at baseline. Journal of Psychosomatic Research, 61, 205-211.

Rajesh, G., Eriksson, M., Pai, K., Seemanthini, S., Naik, D. G., \& Rao, A. (2015). The validity and reliability of the Sense of Coherence scale among Indian university students. Global Health Promotion. https://doi.org/10.1177/1757975915572691

Rohani, C., Khanjari, S., Abedi, H. A., Oskouie, F., \& Langius-Eklöf, A. (2010). Health index, sense of coherence scale, brief religious coping scale and spiritual perspective scale: Psychometric properties. Journal of Advanced Nursing, 66, 2796-2806.

Rostami, R., Lamit, H., Khoshnava, S. M., \& Rostami, R. (2014). The role of historical Persian gardens on the health status of contemporary urban residents: Gardens and health status of contemporary urban residents. EcoHealth, 11(3), 308-321. https://doi. org/10.1007/s10393-014-0939-6

Roth, G., \& Ekblad, S. (2006). A longitudinal perspective on depression and sense of coherence in a sample of mass-evacuated adults from Kosovo. Journal of Nervous and Mental Disease, 194, 378-381.

Sagy, S. (1998). Effects of personal, family, and community characteristics on emotional reactions in a stress situation. Youth \& Society, 29(3), 311-330.

Sagy, S. (2008). Sense of Coherence in a family context. The International Seminar on Salutogenesis and The 1st Meeting of the IUHPE Thematic Working Group on Salutogenesis, Helsinki Finland, 12-13 May, 2008.

Sagy, S., \& Antonovsky, A. (1992). The family sense of coherence and the retirement transition. Journal of Marriage and Family, 54(4), 983-994.

Sakano, J., \& Yajima, Y. (2005). Factors structure of the SOC scale 13 -item version in Japanese university students. Japanese Journal of Public Health, 52(1), 34-45.

Sandell, R., Blomberg, J., \& Lazar, A. (1998). The factor structure of Antonovsky's sense of coherence scale in Swedish clinical and nonclinical samples. Personality and Individual Differences, 24(5), 701-711.

Sardu, C., Mereu, A., Sotgiu, A., Andrissi, L., Jacobson, M. K., \& Contu, P. (2012). Antonovsky's sense of coherence scale: Cultural validation of SOC questionnaire and socio-demographic patterns in an Italian population. Clinical Practice \& Epidemiology in Mental Health, 8, 1-6.

Schnyder, U., Büchi, S., Sensky, T., \& Klaghofer, R. (2000). Antonovsky's sense of coherence: Trait or state? Psychotherapy and Psychosomatics, 69, 296-302.

Schumann, A., Hapke, U., Meyer, C., et al. (2003). Measuring Sense of Coherence with only three items: A useful tool for population surveys. British Journal of Health Psychology, 8, 409-421.

Singer, S., \& Brähler, E. (2007). Die "sense of coherence scale". In Testhandbuch zur deutschen Version. Vandenhoeck \& Ruprecht.

Sotgiu, A., Demurtas, A., Cannas, N., Sias, E., \& Tobarra-López, A. (2018). The Curitiba Statement on Health Promotion and Equity: Italian version and analysis of criticalities. Annali d'giene, 30, 181-190.

Spadoti Dantas, R. A., Silva, F. S., \& Ciol, M. A. (2014). Psychometric properties of the Brazilian versions of the 29- and 13-item scales of the Antonovsky's Sense of Coherence (SOC-29 and SOC-13) evaluated in Brazilian cardiac patients. Journal of Clinical Nursing, 23(1-2), 156-165.

Stern, B., Socan, G., Rener-Sitar, K., Kukec, A., \& Zaletel-Kragelj, L. (2019). Validation of the Slovenian version of the short sense of coherence questionnaire (SOC-13) in multiple sclerosis patients. Zur Varst, 58(1), 31-39.

Söderhamn, O., \& Holmgren, L. (2004). Testing Antonovsky's sense of coherence (SOC) scale among Swedish physically active older people. Scandinavian Journal of Psychology, 45, 215-221.

Söderhamn, U., Sundsli, K., Cliffordson, C., \& Dale, B. (2015). Psychometric properties of Antonovsky's 29-item Sense of Coherence scale in research on older home-dwelling Norwegians. Scandinavian Journal of Public Health, 43(8), 867-874.

Suominen, S., Blomberg, H., Helenius, H., et al. (1999). Sense of coherence and health-does the association depend on resistance resources? Psychology and Health, 14, 937-948.

Suraj, S., \& Singh, A. (2011). Study of sense of coherence health promoting behaviour in north Indian students. Indian Journal of Medical Research, 134, 645-652.

Surtees, P., Wainwright, N., Luben, R., Khaw, K.-T., \& Day, N. (2003). Sense of coherence and mortality in men and women in the EPICNorfolk United Kingdom prospective cohort study. American Journal of Epidemiology, 158(12), 1202-1209.

Tang, S. T., \& Li, C.-Y. (2008). The important role of sense of coherence in relation to depressive symptoms for Taiwanese family caregivers of cancer patients at the end of life. Journal of Psychosomatic Research, 64, 195-203.

Toft Würtz, E., Fonager, K., \& Tølbøll Mortensen, J. (2015). Association between sense of coherence in adolescence and social benefits later in life: a 12-year follow-up study. BMJ Open. https://doi. org/10.1136/bmjopen-2014-006489

Togari, T., Yamazaki, Y., Takayama, T. S., Yamaki, C. K., \& Nakayama, K. (2008). Follow-up study on the effects of sense of coherence on well-being after two years in Japanese university undergraduate students. Personality and Individual Differences, 44(6), 1335-1347. https://doi.org/10.1016/j.paid.2007.12.002

Virues-Ortéga, J., Martinez-Martin, P., Del Barrio, J. L., Lozano, L. M., \& Grupo Espanol, E. (2007). Cross-cultural validation of Antonovsky's Sense of Coherence Scale (OLQ-13) in Spanish elders aged 70 years or more. Medicina Clinica, 128, 486-492.

Vasiliu, D., Marinescu, D.-A., Marinescu, G., \& Rizeanu, S. (2015). Assessing sense of Coherence. Psychometric properties for the sense of coherence scale: SOC-13. May 2015. Conference: Sesiunea de comunicari stiintifice a Universitatii Hyperion At: Hyperion University, Bucharest, Romania.

Vogt, K., Jenny, G. J., \& Bauer, G. F. (2013). Comprehensibility, manageability and meaningfulness at work: Construct validity of a scale measuring work-related sense of coherence. South African Journal of Industrial Psychology, 39(1), 8.

Volanen, S. M., Suominen, S., Lahelma, E., Koskenvuo, M., \& Silventoinen, K. (2007). Negative life events and stability of sense of coherence: A five-year follow-up study of Finnish women and men. Scandinavian Journal of Psychology, 48(5), 433-441.

WHO. (2001). The World health report 2001: Mental health: New understanding, new hope. World Health Organization.

Open Access This chapter is licensed under the terms of the Creative Commons Attribution 4.0 International License (http://creativecommons. org/licenses/by/4.0/), which permits use, sharing, adaptation, distribution and reproduction in any medium or format, as long as you give appropriate credit to the original author(s) and the source, provide a link to the Creative Commons license and indicate if changes were made.

The images or other third party material in this chapter are included in the chapter's Creative Commons license, unless indicated otherwise in a credit line to the material. If material is not included in the chapter's Creative Commons license and your intended use is not permitted by statutory regulation or exceeds the permitted use, you will need to obtain permission directly from the copyright holder. 